\title{
The internal clock hypothesis for astro-navigation in homing pigeons'
}

MERLE E. MEYER

WESTERN WASHINGTON STATE COLLEGE

One of the major assumptions of Matthews' sun-arc hypothesis is that of the internal clock which, together with changes in the arc angle of the sun, is used to estimate longitude. This study investigated birds' ability to make time judgments and concluded that homing pigeons are able to detect time intervals-sufficiently well to navigate. The data would not support pinpoint navigation but are compatible with the the ory.

Matthews (1955) has suggested that birds use the sun for bicoordinate navigation. He hypothesized that the bird assesses the sun's arc and uses the altitude of the highest point to obtain its latitude, and changes in the arc angle together with a measure of time to estimate its longitude. Meyer (1964) has shown that birds were able to detect movement at $15^{\circ}$ an hour, and that they could discriminate changes in altitude and changes in arc angle compatible with Matthews' theory.

One of the major assumptions of Matthews' theory is that of the internal clock or "chronometer". Matthews (1955), Hoffman (1960), and Schmidt-Koenig (1960) have tested the role of the internal clock in homing and navigation studies with birds. In general, the clock has been shifted or reset by placing the animal in an artificial, controlled light source for a period of time, and then the orientation behavior of the birds upon release in the field has been used as the major indicator of the effect of the time variable. Within the field experiments, however, many environmental stimuli may conceal the accuracy of the bird's internal clock.

Adler (1963) reports two experiments within the controlled environment of the laboratory, to measure time judgments by birds. In the first study, starlings were placed on a continuous reinforcement schedule (CRF) during the light period. Under the CRF, "... birds developed a characteristic feeding rhythm showing one or more daily maxima of activity ... This rhythm is synchronized by the day/night cycle"' (Adler, 1963, pp. 246, 247-8). In the second study starlings were tested under a 4-hr. rhythm during four periods daily. The birds received $3 \mathrm{hr}$. of no reinforcement followed by $1 \mathrm{hr}$. of reinforcement on a fixed ratio reinforcement schedule of 20 (FR20). The data shows four peaks of responses just before and during the FR20 periods. The accuracy of the clock on the 4-hr. periodicity was used as an index of the birds' time judgment. Adler estimates an average error of 15-20 $\mathrm{min}$., and when applying these data to celestial navigation at the latitude of $40^{\circ} \mathrm{N}$, a 20-min. error results in a displacement of the bird 265 miles on the east-west axis. These data were used to cast serious doubt on the ability of birds to use such a system for celestial navigation.

As limited data are available for the measurement of time judgments that the bird may be making, this laboratory study was carried out.

General Experimental Procedures

Subjects. The Ss were two 4-year-old cock homing pigeons, No. 3838 and No. 3892. These birds had no prior experimental history in the laboratory, however, they had prior successful homing experiences. Preceding the experiment, the Ss were held at $80 \% \pm 10 \mathrm{gm}$ of their ad lib weight. Each $S$ was then magazine trained and shaped to peck the response key. The Ss were given $1 \mathrm{hr}$. on a CRF schedule and were retained in the experimental chamber for the remainder of the experiment. During the experiment proper, the birds were on a 23-hr. food deprivation schedule. The S was removed from the chamber semi-weekly during the dark period for cleaning and the loading of the food and water hoppers.

Apparatus. The experimental chamber was an operant box for pigeons and housed in a light-tight chamber. A white noise was used throughout the study as an auditory mask. The food magazine was programmed to give free access to grain for an interval of $4 \mathrm{sec}$. The light onset and the dark onset, the time intervals, and all the scheduling of the reinforcement contingencies were automatic. The number of responses and timing errors were recorded on counters and on a cumulative recorder.

Procedures. The general procedure was that of the onset of the house light in the enclosed operant chamber was followed by time before the beginning of the CRF reinforcement schedule. During the first phase of the study the interval of time between the onset of the house light and the reinforcement period was $30 \mathrm{~min}$.; in the second phase, $1 \mathrm{hr}$; and in the last phase, $2 \mathrm{hr}$. The house light was on for $12 \mathrm{hr}$. and off for the same period of time, thus constituting one trial a day. The reinforcement period was held throughout the experiment for $1 \mathrm{hr}$. on a CRF schedule. The accuracy of the internal clock was measured in time from the first response made to the beginning of the reinforcement period. Results and Discussion

An illustrative example of the bird's time judgment as measured in terms of anticipation errors is shown in Fig. 1. These data are for bird No. 3838 where the time interval between light onset and the reinforcement period was $30 \mathrm{~min}$. As can be seen from the figure, the errors in time judgment show a considerable amount of trial variability. Nonetheless, when the data are 


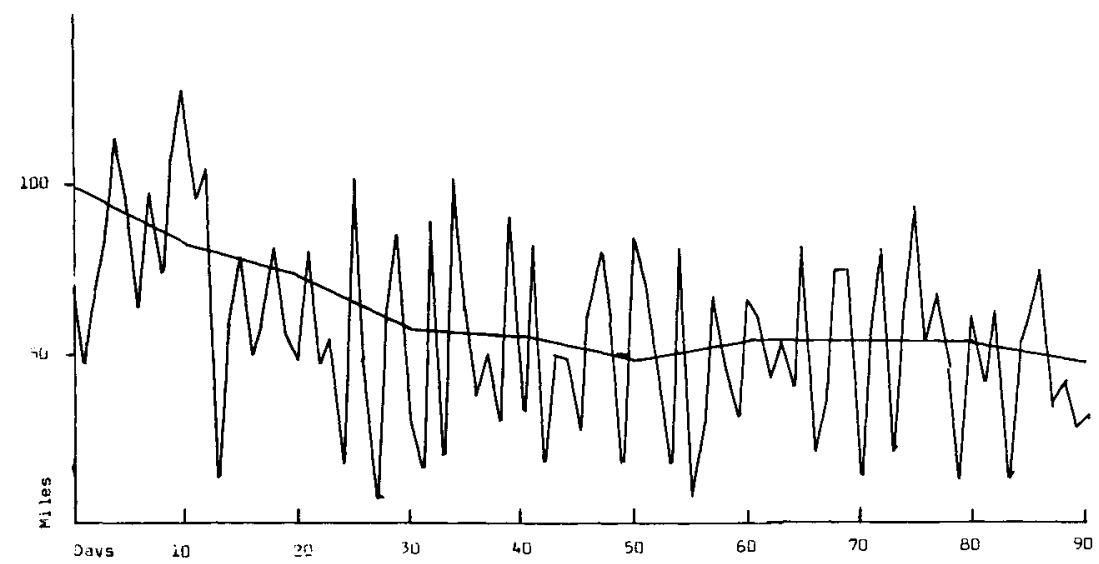

Fig. 1. Errors in 30-min. time judgments as estimated in miles of displacement for Bird No. 3838 for the last 90 trials.

blocked in 10-day intervals, a trend for the last 100 trials is clearly evident. When the time interval was shifted to $1 \mathrm{hr}$. and then to $2 \mathrm{hr}$., and after further training, similar general results occurred on the last series of 100 trials. With a composite for the three time intervals and for the data from the two $\mathrm{Ss}$, it was estimated that the errors in time judgments for $45^{\circ} \mathrm{N}$ would give rise to a displacement of the bird between 50 and 60 miles on the east-west axis.

The general results lend support for the internal clock hypothesis in demonstrating that birds were able to discriminate time intervals, at least when the Ss were trained to do so. The data, as observed in this study, would not confirm a perfect functioning clock for pin-

point navigation, but the measured values provide data compatible with Matthews' theory.

\section{References}

Adler, H. E. Psychophysical limits of celestial navigation hypothesis. Ergebnisse der Biologie, 1963, 26, 235-252.

Hoffmann, K. Experimental manipulation of the orientational clock in birds. Cold Spr. Harb. Symp. quant. Biol., 1960, 25, 379-387.

Matthews, G. V. T. Bird navigation. Cambridge: Cambridge University Press, 1955.

Meyer, M. E. Discriminative basis for astronavigation in birds. $J$. comp. physiol. Psychol., 1964, 58, 403-406.

Schmidt-Koenig, K. Internal clocks and homing. Cold Spr. Harb. Symp. quant. Biol., 1960, 25, 380-393.

\section{Note}

1. This study was supported in part by a grant from the Society of The Sigma Xi and RESA Research Fund. 